\title{
Hiatal Hernia by Rolling Revealed by Respiratory Symptoms: A Rare Condition and Atypical Presentation
}

\author{
Hind Serhane, Othmane Ouardi, Hafsa Sajiai, Selma Aitbatahar, Lamyae Amro \\ Department of Respiratory Medicine, Laboratory PCIM, Faculty of Medicine and Pharmacy, Cadi Ayyad University, Marrakesh, Morocco \\ Email: hindserhane8@gmail.com
}

How to cite this paper: Serhane, H., Ouardi, O., Sajiai, H., Aitbatahar, S. and Amro, L. (2016) Hiatal Hernia by Rolling Revealed by Respiratory Symptoms: A Rare Condition and Atypical Presentation. Case Reports in Clinical Medicine, 5, 330-334. http://dx.doi.org/10.4236/crcm.2016.59050

Received: February 16, 2016

Accepted: September 25, 2016

Published: September 28, 2016

Copyright $\odot 2016$ by authors and Scientific Research Publishing Inc. This work is licensed under the Creative Commons Attribution International License (CC BY 4.0).

http://creativecommons.org/licenses/by/4.0/

\section{Abstract}

Hiatal hernia by rolling is a rare pathology estimated at 5\% of all diaphragmatic hernias. It is usually asymptomatic. Sometimes, it can be accompanied by different symptoms, such as post prandial bloating, dysphagia, regurgitation, retro sternal pain, even respiratory symptoms. The aim of this article is to show that a hiatus hernia by rolling can cause a misleading clinical picture that may be taken wrongly for a heart or respiratory disease. We report the case of an 80-year-old patient whose presentation was suggestive of an acute heart condition, but the scan confirmed a rolling diaphragmatic hernia. Because of the rarity and the atypical presentation of this case, we have found it desirable to bring this new observation.

\section{Keywords}

Hiatal Hernia, Diaphragmatic Hernia, Rolling Hernia, Retrosternal Pain, Respiratory Symptoms

\section{Introduction}

The diaphragmatic hernia is defined by permanent or intermittent passage of the abdominal viscera in the chest by an abnormal diaphragmatic hole. This diaphragmatic hole may be abnormally far (Larrey slot, Bochdalek hernia) or abnormally enlarged (hiatal hernia). Hiatal hernias are due to movement of the gastroesophageal junction into the thorax. There are 3 types of hiatal hernia:

- The most frequent (85\% of cases) are sliding hernias.

- Hernias by rolling ( $5 \%$ of cases), in which the cardia is intra-abdominal and fundus in intrathoracic position.

- Mixed hernias (10\% of cases). 
The rotating hiatal hernias do not cause gastroesophageal reflux or esophagitis.

The symptoms are related to the volume of the hernia, which can manifest as chest pain angina, respiratory symptom, sometimes chronic anemia. Complications are represented by gastrointestinal bleeding related to ulceration of the neck hernia (see necrosis and perforation of the collar, mediastinitis, and gastric volvulus). Because of the risk of complications, surgical indication arises when the diagnosis of hiatal hernia is made.

Given the rarity of this disease, we report the case of a patient admitted to our department for respiratory symptoms revealing hiatal hernia by rotation.

\section{Case Report}

Mrs. L A, 80 years old, with a history of dyslipidemia and type II diabetes put on oral anti-diabetic and placed under symptomatic treatment for gastroesophageal reflux 10 years ago. This patient was presented to the emergency room in an array of acute retrosternal chest pain, chronic dyspnea since 3 months, associated with a dry cough without hemoptysis nor dysphagia, nor hydatidoptysis or other respiratory or extra-respiratory signs associated. Clinical examination showed an obese patient with a BMI 26 $\mathrm{kg} / \mathrm{m}^{2}$, tachypnea at 20 cycles/minute, cyanosis of the lips and extremities, $87 \% \mathrm{SaO}_{2}$ in the ambient air, without rattling in auscultation. The cardiac examination has not objectified abnomally outside except a tachycardia of 110 beats/minute. Ischemic heart disease was mentioned in the first place (according to age and cardiovascular risk factors presented by the patient). Troponin, ECG and echocardiography had not objectified signs for cardiac ischemia. Chest radiograph Figure 1 suggested the existence of some retrocardiac clarities, with horizontal air-fluid levels suggesting a diagnosis of a diaphragmatic hernia. After stabilization of the patient, a chest CT scan was requested (Figure 2) showing a large defect of the left diaphragm with ascension through the esophageal hiatus of the large gastric tuberosity, of the $2 / 3$ of the stomach and perigastric fat on retrocardiac region of the posteroinferior mediastinum. This CT aspect is suggestive of a hiatal hernia by rolling. Surgical treatment was proposed to the patient, but given the age and the medical history of the patient, surgery seemed to bring more risk than benefit. Therefore, we opted to keep it under strict surveillance to detect possible complications. A rhythm of regular monitoring has been proposed to the patient every 3 months. Lifestyle and dietary rules and anti reflux treatment have been proposed for the patient. The patient evolved well, no complications did not occur after 18 months.

\section{Discussion}

Diaphragmatic hernia rotating or para esophageal hernia or hiatal firewall represents $5 \%$ of hiatal hernias. The hernia orifice has often variable diameter [1]. The omentum is uniquely the only herniated structure in almost all cases, the bag contains all or a part of the stomach, as the case of our patient. In fact, the content of the hernia sac depends on the volume of the hernia. In small hernia, only the gastric fundus is intrathoracic. In large hernias, all the stomach switches from the left to the right around the small curvature into the thorax, realizing volvulus organoaxial [2]. In the voluminous hernias 


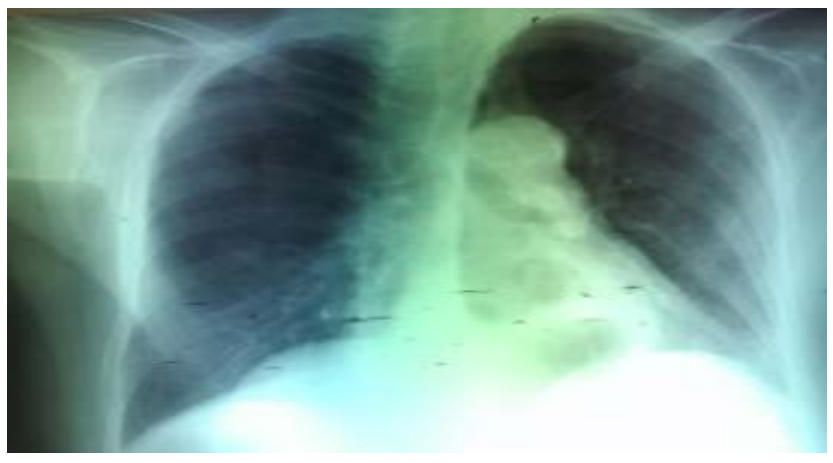

Figure 1. Retrocardiac clarities, with horizontal air-fluid levels.

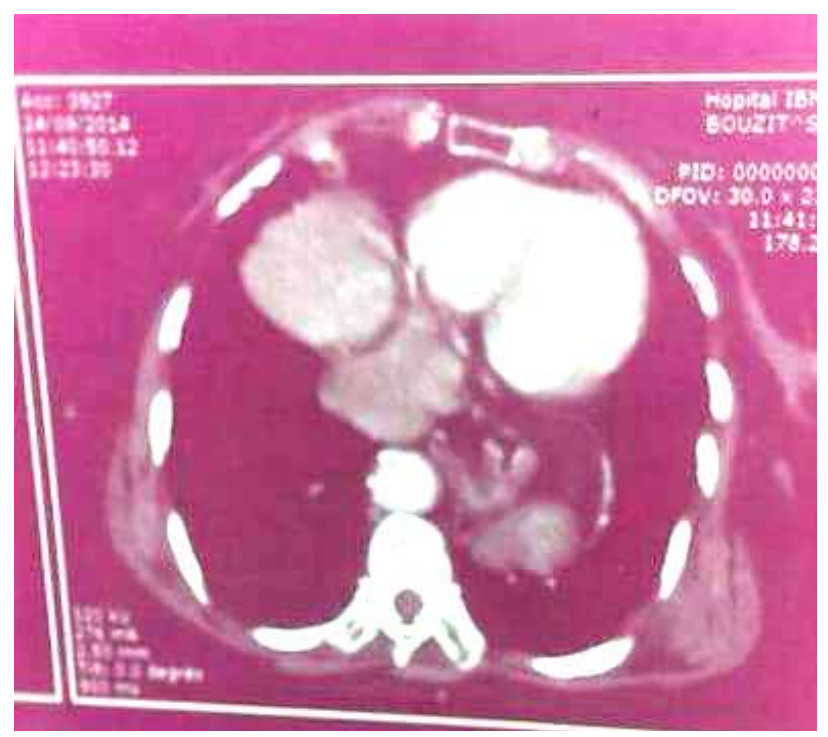

Figure 2. Large defect of the left diaphragm with ascension through the esophageal hiatus of the large gastric tuberosity, of the $2 / 3$ of the stomach and perigastric fat on retrocardiac region of the posteroinferior mediastinum.

omentum, transverse colon, spleen or even hail can engage with stomach. Hernia occupies the lower posterior mediastinum behind the heart and in front of the esophagus. Usually the cardia remains in place with an intact ligament and a normal configuration of the His angle [3]. The gastro esophageal reflux is the most common symptom [4]. It is frequently observed in women 70 to 80 years as the case of our patient. Thoracic manifestations are the prerogative of young subjects, their appeared or worsened in postprandial and are frequently accompanied by intermittent symptoms of oesophageal or pyloric obstruction (dysphagia, vomiting) and often iron deficiency anemia with or without signs of digestive hemorrhage [5]. The respiratory symptoms can be present regardless of the size of the hernia, such as dyspnoea and chest pain that gets worse especially in postprandial, this was the case of our patient. The diagnosis is suggested by the presence of one or much retrocardiac clarity containing a hydroaeric level lateralized to the right when it is voluminous. This X-ray image increases in volume after in- 
gestion of a soft drink. It is usually accompanied by a disappearance of the gastric air pocket. The latter may still be in place, chest radio while revealing two clarities with hydro aeric level, one above, the other under diaphragmatic indicating a cascade stomach. When the hernia is large, it can be observed in addition to gastric hernia image, evocative clarities of colic hernia and/or opacity of a herniated spleen. So, any clarity of the postero-inferior mediastinum with hydro aeric level must lead to gastroesophageal transit that will affirm the diagnosis and eliminate other conditions sometimes evocated (bronchogenic cyst, abscess of the mediastinum...) [6]. In our patient, the diagnosis was suggested on chest radiograph, which showed the retro-cardiac clarities, which can be relevant to digestive clarities. CT allows affirming the epiploic hernia (a fat mass having an omental aspect occupying the postero-inferior mediastinum extending through the esophageal hiatus with intra abdominal omentum) [7]. In our patient, CT showed a climb through the oesophageal hiatus of the large gastric tuberosity, of $2 / 3$ of the stomach and the perigastric fat in retrocardiac region at posteroinferior mediastinum. The complications are the hemorrhages by ulceration or necrosis of the collet with perforation and mediastinitis, or acute stomach volvulus. Conversely to hiatal hernias by sliding, the risk of occurrence of acute complications of hernia by rolling is for all authors are a formal indication for surgery. The surgical treatment of hiatal hernia by rolling requires resection of the hernia sac, suture of the pillars of the esophagus and the making of a Nissen or toupet fundoplication. Moreover, the advent of laparoscopy 10 years ago transformed the surgical treatment of hiatal hernias. It is now possible to reproduce in laparoscopy the same techniques as those used in conventional surgery by laparotomy. Our patient given her age and her major clinical history, was refused from surgery, but close monitoring has been proposed for her to watch for possible complications.

\section{Conclusion}

The hiatal hernia by rolling remains fairly a rare disease. Diagnosis can be made by simple chest X-ray. We have to think about in case of gastroesophageal reflux with respiratory symptoms worsening especially in post-prandial. The treatment is surgical, and can avoid complications. But we must always consider the benefit risk before starting a surgical cure and prefer laparoscopy if it is available.

\section{Conflicts of Interest}

Authors declare they have no conflicts of interest.

\section{References}

[1] Wichterman, K., Geha, A.S., Cahow, E. and Baue, A.E. (1979) Giant Paraoesophageal Hiatus Hernia with Intrathoracic Stomach and Colon: The Case for Early Repair. Surgery, 86, 497-506.

[2] Dubost, C.I., Kaswin, K., Brumpt, B. and Celerier, M. (1973) Volvulus, incarcération, étranglement de l'estomac dans les grosses hernies hiatales paraoesophagiennes. Journal de 
Chirurgie, 106, 195-212.

[3] Pearson, F.G., Cooper, J.D., Ilves, R., Todd, T.R. and Jamieson, W.R. (1983) Massive Hiatal Hernia with Incarceration. A Report of 53 Cases. The Annals of Thoracic Surgery, 35, 45-51. http://dx.doi.org/10.1016/S0003-4975(10)61430-0

[4] Allen, M.S., Trastek, V.F., Dechamp, C. and Pairolero, P.C. (1993) Intra Thoracic Stomach. Presentation and Results of Operation. The Journal of Thoracic and Cardiovascular Surgery, 105, 253-259.

[5] Le Brigand, H., Rojas-Miranda, A. and Dartevelle, Ph. (1980) Piège diagnostiques des hernies diaphragmatiques. Concours Med, 102, 3345-3363.

[6] Coulamb, M., Terraube, Ph., Lebas, J.F., Chouteau, H. and Geindre, M. (1981) Amas graisseux intra thoraciques symptomatiques d'une hernie diaphragmatique chez l'adulte. A propos de 11 observations avec étude tomodensitométrique. Journal de Radiologie, 62, 85-95.

[7] Fingerhunt, A., Pourcher, J., Pelletier, J.M., et al. (1978) Deux observations de hernie diaphragmatique poséro-latérale congénitale (dite de Bochdalek) révélée à l'âge adulte par des complications sévères. Intervention et guérison. Revue de la littérature. Journal de Chirurgie, 115, 135-143.

Submit or recommend next manuscript to SCIRP and we will provide best service for you:

Accepting pre-submission inquiries through Email, Facebook, LinkedIn, Twitter, etc. A wide selection of journals (inclusive of 9 subjects, more than 200 journals)

Providing 24-hour high-quality service

User-friendly online submission system

Fair and swift peer-review system

Efficient typesetting and proofreading procedure

Display of the result of downloads and visits, as well as the number of cited articles

Maximum dissemination of your research work

Submit your manuscript at: http://papersubmission.scirp.org/

Or contact crcm@scirp.org 